Review

\title{
Comprehensive Review on Smart Techniques for Estimation of State of Health for Battery Management System Application
}

\author{
Sumukh Surya ${ }^{1, *\left(\mathbb{D}, \text { Vidya } \text { Rao }^{2} \text { iD }\right.}$ and Sheldon S. Williamson ${ }^{3, *}$ \\ 1 ePowerTrain, Kirtane Pandit Information Technology (KPIT), Bangalore 560103, India \\ 2 Department of Information Science and Engineering, Jyothy Institute of Technology, Bangalore 560082, India; \\ vidyarao1988@yahoo.com \\ 3 Department of Electrical, Computer and Software Engineering, Faculty of Engineering and Applied Science, \\ University of Ontario Institute of Technology, Oshawa, ON L1G 0C5, Canada \\ * Correspondence: sumukhsurya@gmail.com (S.S.); sheldon.williamson@uoit.ca (S.S.W.)
}

check for updates

Citation: Surya, S.; Rao, V.; Williamson, S.S. Comprehensive Review on Smart Techniques for Estimation of State of Health for Battery Management System Application. Energies 2021, 14, 4617. https://doi.org/10.3390/en14154617

Academic Editor: Teuvo Suntio

Received: 4 July 2021

Accepted: 26 July 2021

Published: 30 July 2021

Publisher's Note: MDPI stays neutral with regard to jurisdictional claims in published maps and institutional affiliations.

Copyright: (c) 2021 by the authors. Licensee MDPI, Basel, Switzerland. This article is an open access article distributed under the terms and conditions of the Creative Commons Attribution (CC BY) license (https:// creativecommons.org/licenses/by/ $4.0 /)$.

\begin{abstract}
Electric Vehicles (EV) and Hybrid EV (HEV) use Lithium (Li) ion battery packs to drive them. These battery packs possess high specific density and low discharge rates. However, some of the limitations of such $\mathrm{Li}$ ion batteries are sensitivity to high temperature and health degradation over long usage. The Battery Management System (BMS) protects the battery against overvoltage, overcurrent etc., and monitors the State of Charge (SOC) and the State of Health (SOH). SOH is a complex phenomenon dealing with the effects related to aging of the battery such as the increase in the internal resistance and decrease in the capacity due to unwanted side reactions. The battery life can be extended by estimating the $\mathrm{SOH}$ accurately. In this paper, an extensive review on the effects of aging of the battery on the electrodes, effects of Solid Electrolyte Interface (SEI) deposition layer on the battery and the various techniques used for estimation of $\mathrm{SOH}$ are presented. This would enable prospective researchers to address the estimation of $\mathrm{SOH}$ with greater accuracy and reliability.
\end{abstract}

Keywords: Battery Management System; data driven techniques; hybrid electric vehicles; Li ion; SEI layer; $\mathrm{SOH}$

\section{Introduction}

Traditional Vehicles use fossil fuels to drive them. These vehicles emit Green House Gases (GHG) and pollute the atmosphere. Hence, electrification of the current transportation is necessary to prevent air pollution. In this regard, various energy storage devices are used in Electric Vehicles (EV) namely 1. Battery, 2. Ultra Capacitor, 3. Fuel Cell and 4. Ultra- Capacitor [1].

The classification of energy storage devices is based on their functionality and the type of energy stored. Figure 1 shows the classification of various energy storage devices $[1,2]$.

Classification of Energy Storage Devices
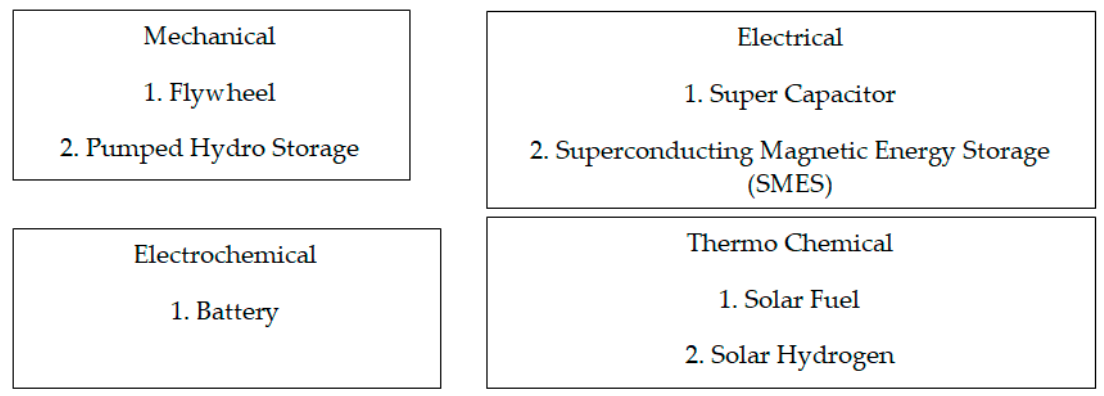

Figure 1. Classification of Energy Storage Devices [1]. 
Among the various energy storage devices, Li ion batteries are preferred due to the following reasons namely (1) High Power Density, (2) High Energy Density (3) Light Weight and (4) High Terminal Voltage. Table 1 shows a comparative analysis of various energy storage devices.

Table 1. Comparative analysis of various energy storage devices.

\begin{tabular}{ccccc}
\hline $\begin{array}{c}\text { Energy Storage } \\
\text { Device }\end{array}$ & $\begin{array}{c}\text { Power Range } \\
\text { (MW) }\end{array}$ & $\begin{array}{c}\text { Energy Density } \\
\mathbf{( W h / I )}\end{array}$ & $\begin{array}{c}\text { Power Density } \\
\mathbf{( W h / I )}\end{array}$ & Efficiency \\
\hline $\begin{array}{c}\text { Pumped Hydro } \\
\text { Storage }\end{array}$ & $10-5000$ & $0.5-1.5$ & $0.5-1.5$ & $75-85$ \\
\hline SMES & $0.1-10$ & $0.2-2.5$ & $1000-4000$ & $95-98$ \\
\hline Li-ion & $0-100$ & $200-500$ & $500-2000$ & $90-97$ \\
\hline
\end{tabular}

Figure 2 depicts the block diagram of a Plug-In Hybrid EV (PHEV) wherein the battery present in PHEV can draw and store energy from the electric grid or renewable sources [3].

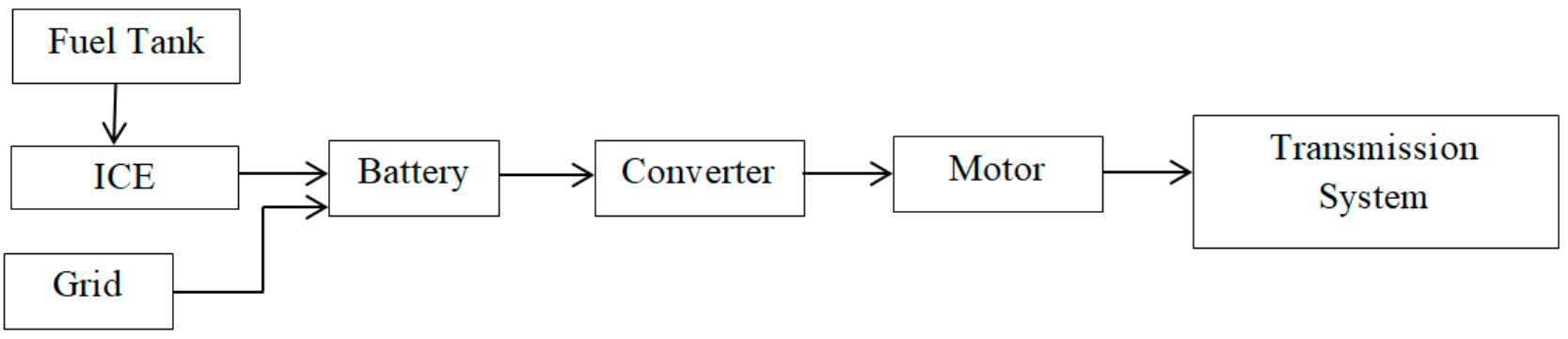

Figure 2. Block Diagram of a PHEV.

An Internal Combustion Engine (ICE) is powered by the fossil fuel stored in the fuel tank. ICE powers the motor and torque is generated which is fed to the transmission system. Meanwhile, the power to the motor can also be fed from the grid or other renewable source of energy. The BMS controls the charging current voltage and provides protection to the battery. Figure 3 shows the functionality of BMS in EV application. The BMS takes input from the battery pack and provides control signals to turn ON/OFF the contactor, thermal management and protects the battery pack [4].

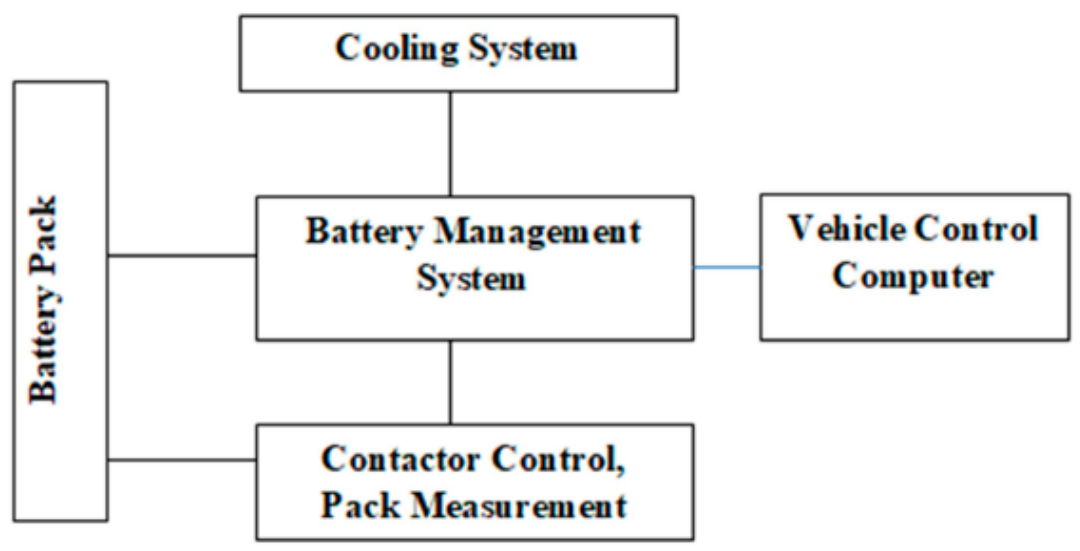

Figure 3. BMS Functionality.

Estimation of SOC, SOH and Core Temperature are the most fundamental algorithms in BMS application. Some of the advantages of estimating SOH for batteries are (a) Timely replacement (b) Increase in life and (c) Reliable operation. SOH is considered as one of 
indictors for aging phenomena and involves estimating the series internal resistance (Power Fade) and the nominal capacity (Capacity Fade) of the battery or a cell. Power and Capacity fading are complicated features as they do not occur simultaneously [5]. These occur due to the unwanted side reactions and result in structural deterioration. Li moves to and fro from the positive and negative electrodes. Ideally, no $\mathrm{Li}$ ion is lost during this movement. However, in practice Li ion is carried away while moving between the electrodes in the side reaction. This phenomenon is called Loss of Li inventory (LLI) and this occurs charging. Hence, the amount of Li stored in a cell/battery decreases. This is referred to as Loss of Active Material (LAM).

$$
S+2 e^{-}+2 \mathrm{LiPF}_{6} \rightarrow \mathrm{SLi}_{2}+2 \mathrm{PF}_{6}
$$

The solvent $S$ at the anode consumes two $L i$ ions and forms partially soluble Dilithium Sulphide and causes the SEI formation [6].

Measuring the capacity of the battery cell is extremely important as for calculating the total energy that can be held in the battery cell as SOC computation requires capacity measurement. The internal resistance plays a vital role during power calculation and SOC estimation based on voltage-based methods [5,7].

To estimate the $\mathrm{SOH}$, cell modeling is extremely important. A cell is considered as the fundamental unit in a battery and can be modeled as a pair of Resistor-Capacitor (RC) pair by providing a pulse discharge using Pulse Characterization Test $[7,8]$. Figure 4 shows the voltage profile used for estimating the battery parameters. Lesser computation effort is required to estimate $1 \mathrm{RC}$ parameter value for a cell model. To perform the pulse characterization test, a discharge current is applied initially. Hence, the voltage drops due to the discharge current. The procedure to estimate the battery parameters were shown in [7].

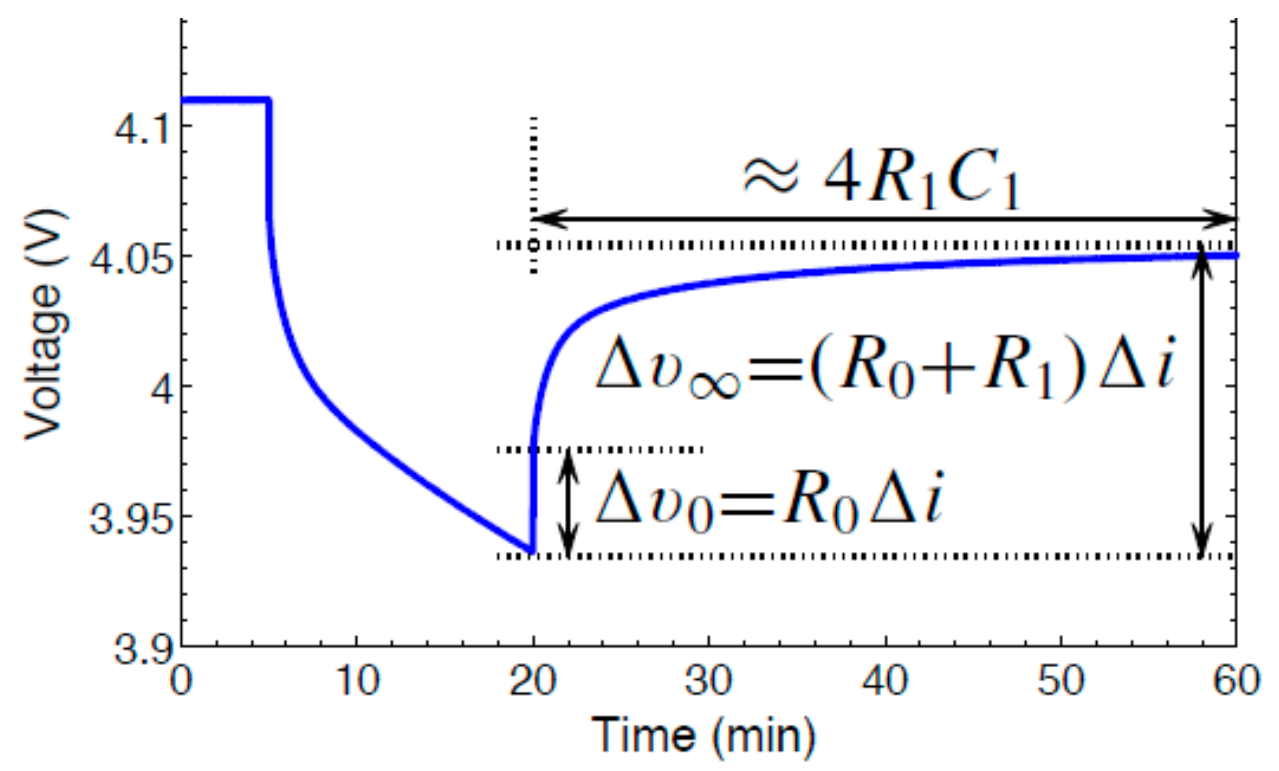

Figure 4. Polarization of Voltage.

The internal series resistance in addition to the parallel RC pair constitutes 1-RC pair model of a cell. The best battery model consists of 5-RC pairs and is termed as Enhanced Self Correcting Model $[9,10]$ which provides accurate results. The battery parameters showed dependence on SOC but not on the magnitude of discharge current and ambient temperature. The empirical formula based on 2-RC pairs for Randles circuit was presented in [11]. The Open Circuit Voltage (OCV) based SOC model was presented for Li Iron Phosphate chemistry (LiFePO4). A comparative analysis on different methodologies involved in $\mathrm{SOH}$ estimation is presented. In Direct method, the internal resistance is 
directly measured as a function of temperature. However, in Degradation model the active material present in the battery is measured. This method provides highly accurate result and requires intense computation. Hence, high cost is involved.

Due to the increase in the temperature, $\mathrm{SOH}$ degradation takes place. The core or the internal temperature $\left(T_{c}\right)$ of a cell can reach to dangerously large values under fast current discharge. For $2 \mathrm{C}$ discharge current, $\mathrm{T}_{\mathrm{c}}$ increased 6-7 times than that of the surface temperature, $\mathrm{T}_{\mathrm{S}}$ [12]. Since, $\mathrm{Li}$ ion cells are very sensitive to high temperature; they catch fire leading to thermal run-away. Hence, thermal management is essential part of BMS. $T_{c}$ was estimated using Kalman Filter for different chemistries and the difference between $\mathrm{T}_{\mathrm{S}}$ and $\mathrm{T}_{\mathcal{C}}$ were shown in [13-15]. The internal resistance showed low value for high temperatures. When the SOC varied from $0-100 \%$, the internal resistance value was low. However, the value was negligible for SOC between 20-80\% [16].

Some of the typical DC - DC converters used for charging applications in EV industry are Cuk and SEPIC as they possess series inductor with the input voltage supply $[17,18]$ providing continuous input current. In [19], $\mathrm{SOH}$ of battery coupled to a Bi-directional DC-DC converter is estimated based on temperature, $C$ rate and Depth of Discharge (DOD). One of major drawback from this system is that error is found to increase in SOC estimation due to battery aging. Hence, the proposed $\mathrm{SOH}$ technique is specific to the system and needs information on battery pack capacity and capacity at various $C$ rates.

In [20], SOH balancing for two cells is performed by connecting series DC-DC converters. The reference signals of current are generated by the controller for discharging and charging currents. Due to efficient balancing, the cells reduce to the lowest $\mathrm{SOH}$ enabling safely and timely replacement. This scheme can be used for estimating the second life of the battery.

A comparative analysis on different methodologies involved in $\mathrm{SOH}$ estimation is presented in [21]. In Direct method, the internal resistance is directly measured as a function of temperature. However, in Degradation model the active material present in the battery is measured. This method provides highly accurate result and requires intense computation. Hence, high cost is involved. Table 2 shows a comparison between direct methods and degradation models used for estimating $\mathrm{SOH}$.

Table 2. Direct methods Vs. Degradation Models.

\begin{tabular}{cccccc}
\hline SL.NO & Method & Overview & Technique & Merit & Demerit \\
\hline 1 & Direct & $\begin{array}{c}\text { Uses voltage, } \\
\text { current and } \\
\text { temperature }\end{array}$ & Offline & $\begin{array}{c}\text { Easy and } \\
\text { Efficient }\end{array}$ & Difficult to measure \\
\hline 3 & Degradation & $\begin{array}{c}\text { Requires } \\
\text { knowledge of } \\
\text { electrochemistry }\end{array}$ & Offline & High Accuracy & Complex \\
\hline & $\begin{array}{c}\text { Impedance } \\
\text { Spectroscopy }\end{array}$ & Estimates SOH & Offline & Accurate & $\begin{array}{c}\text { Specified instruments } \\
\text { required and time } \\
\text { consuming }\end{array}$ \\
\hline
\end{tabular}

Estimation of 2nd life is a popular technique to predict how quickly the battery can degrade considering the current conditions of the battery as shown in Figure 5. Few advantages of estimating the 2nd life are (a) Lesser price for EV (b) Material and Energy savings [22]. This was due to the fewer side reactions at the graphite anode electrode. Due to this, a thicker and stronger SEI is formed during the aging process. Tests were conducted on three batteries for full cycle each month after which they were subjected to calendar aging. The cells did not exhibit major aging even up to $50 \%$ of capacity degradation, indicating a long battery life in the second life application. Lower capacity fade was seen in cells with SOC $=90 \%$ than in case of cells having SOC $=50 \%$. This can be extremely useful for Uninterruptible Power Supply (UPS) application. 


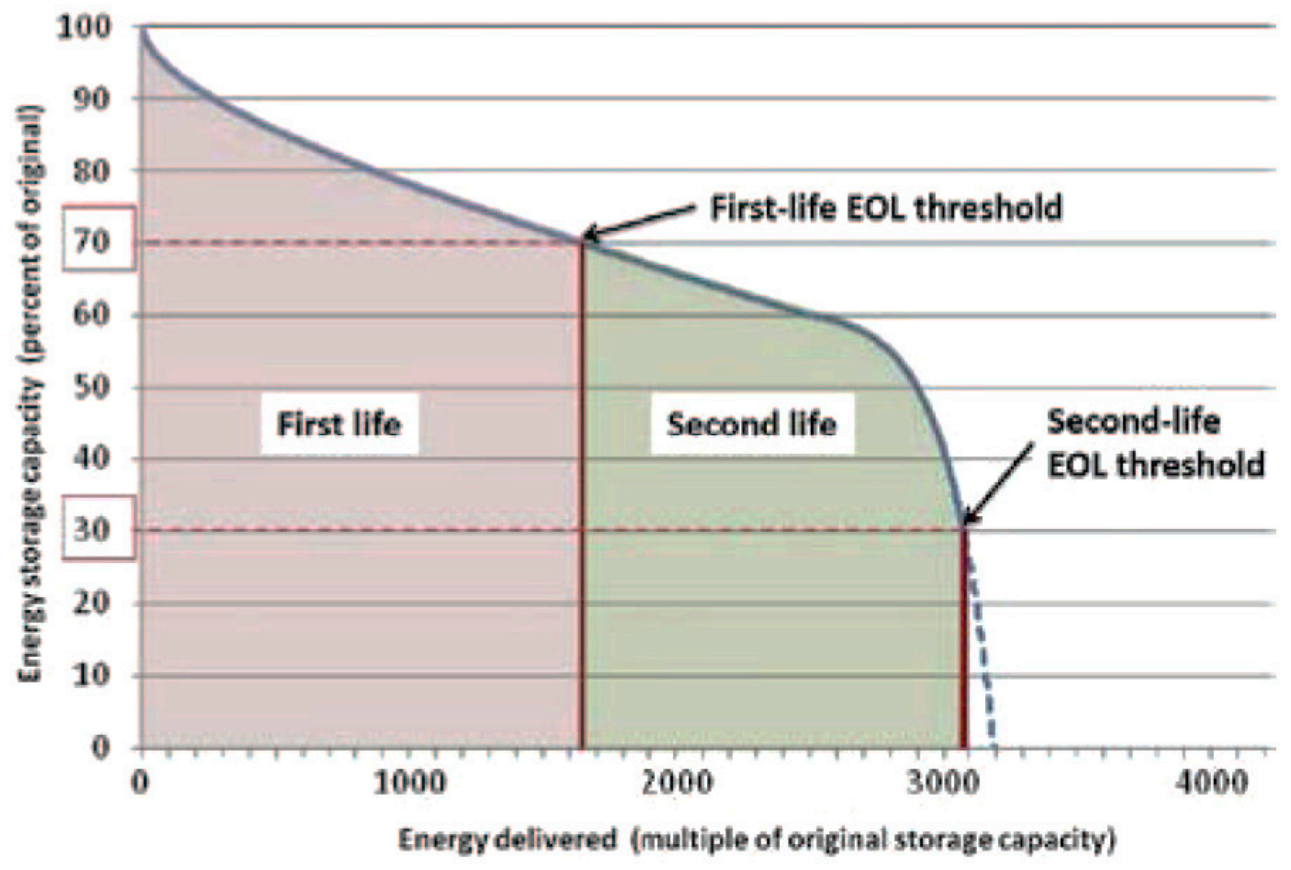

Figure 5. Estimation of Second Life of Batteries [22].

The remaining capacity / power in a cell can be estimated using 1st and 2nd Life Aging. $\mathrm{Li}$ ion cell is considered to be in its EOL stage when operating at $80-85 \%$ of nominal capacity. Using the technique of impedance spectroscopy, second life of a 20Ah Li NMC battery is estimated after EOL at various rated capacities. Randles circuit was used for analyzing the experimental impedance data. It was found that $R_{1}$ and $R_{2}\left(R_{S E L}\right.$ and $\left.R_{C T}\right)$ varied with SOC. These variations were majorly observed during higher SOC range. It was noted this technique cannot be useful while estimating SOC for Li ion cells.

To achieve high efficiency and increased power output smart BMS is proposed. Cloud based BMS using Cyber Hierarchy and International Network (CHAIN) enables provision to realize advance algorithms such as $\mathrm{SOH}$ estimation, thermal management and fault diagnosis. The battery monitoring system helps in visualizing the battery data and supports development of new control strategies [23].

The different materials used in the current collectors are shown in [24].

Data-driven methods such as Machine learning (ML) and Artificial Intelligence (AI) contribute primarily in $\mathrm{SOH}$ estimation. Some of the most common estimation models that can be considered under ML are Recurrent Neural Network (RNN), Support Vector Machines (SVM), Feed-Forward Neural Network (FNN), Regression Model, Clustering Models and many more [25-42].

An attempt is made to provide an exhaustive overview on the existing and upcoming technological advancements in SOH estimation for BMS application. The main reason for health degradation, effects on negative and positive electrodes, effects of SEI on the capacity, traditional and data driven methods for estimating $\mathrm{SOH}$ are addressed. The work is organized as follows: Sections 1 and 2 gives an insight on aging effects on the negative and positive electrodes, respectively. Section 3 addresses the different methods of estimating $\mathrm{SOH}$ using traditional methods and their limitations. Section 4 provides an insight on $\mathrm{SOH}$ estimation using data driven techniques.

\section{Aging Effects at Negative Electrode}

Graphite and Silicon are used material for the negative electrode. At the negative electrode, aging happens in three different scales at three different locations namely, 
(a) On the surface of the electrode

(b) Within the electrode particles and

(c) Within the electrode structure

The graphite negative electrode operates at potentials outside the electrochemical stability window of the electrolyte components used in Li ion cells. Hence, when the electrolyte which are typically organic in nature, comes in contact with graphite and specifically when the graphite is in a charged state, electrolyte decomposes and undergoes a chemical reaction. This creates a thin film layer on the surface of the electrolyte. This layer is referred to as Solid Electrolyte Interface (SEI). This formation layer is primarily created when the cell is charged initially. This layer covers up all the surfaces of the particles. The cell is fully discharged when it is dissembled and later charged so as to move Li from positive to negative electrode.

Some of the properties of SEI are:

a. It is an unwanted layer which consumes $\mathrm{Li}$ in the process of being generated. This in turn reduces the cell capacity.

b. This layer is not reactive but forms insulation between the graphite material and the electrolyte. However, without the layer formation charging cannot be performed.

c. Complex layer and not uniform-Different materials are formed during the reaction and these are deposited on the surface of the electrode. However, the layer itself can decompose and create more stable products than the previously formed.

d. SEI layer has large porous allowing the mixing of materials. However, it creates opposition to the motion of $\mathrm{Li}$ ions. Hence, resistance of the cell increases.

e. The breakdown of the SEI layer can occur due to high temperature. The SEI layer is removed and free layer of graphite is made available to the solvent, creating new SEI layers when temperature is induced. Hence, the net change results in lowering of cell capacity.

f. While manufacturing the cell, maximum effort is made to ensure that no moisture content is in the air. However, it is impossible to eliminate moisture in a cost-effective way and there would be traces of water $\left(\mathrm{H}_{2} \mathrm{O}\right)$ in the electrolyte. This combines with Ionized Fluorine salt $\left(\mathrm{LiPF}_{6}\right)$ in the electrolyte. Hydrogen and Fluorine combines to form Hydrofluoric acid. This acid again decomposes the SEI layer creating a decrease in battery capacity. Hence, breakdown of SEI layer is undesirable.

At low temperatures, the diffusion of particles inside the electrode and the electrolyte decreases. During forced charging, there is a possibility of Li metal formation instead of $\mathrm{Li}$ ion. This is termed as Li plating. This causes the capacity to lose irreversibly and is very rapid. A tree-like structure is formed when this occurs repeatedly called 'Dendrites'. These protrude through the separator. This forms a bridge through the separator from the negative electrode to the positive electrode. This in turn creates local heating and finally results in thermal runaway. Hence, it is not recommended to perform charging of the battery under cold conditions. Table 3 shows the surface effects on the negative electrode of the battery.

Table 3. Surface Effect on the Negative Electrode.

\begin{tabular}{cccc}
\hline Reason & Effect & Leading to & Enhanced by \\
\hline $\begin{array}{c}\text { Continuous low-rate } \\
\text { electrolyte decomposition } \\
\text { build SEI }\end{array}$ & Loss of Li & Capacity Fade & $\begin{array}{c}\text { High Temperature } \\
\text { and SOC }\end{array}$ \\
\hline $\begin{array}{c}\text { Li plating and electrolyte } \\
\text { decomposition }\end{array}$ & $\begin{array}{c}\text { Rise in } \\
\text { Impedance }\end{array}$ & Power Fade & $\begin{array}{c}\text { High Temperature } \\
\text { and SOC }\end{array}$ \\
\hline $\begin{array}{c}\text { Changes in Volume and } \\
\text { SEI growth }\end{array}$ & Loss of Li & Capacity Fade & $\begin{array}{c}\text { Low temperature and } \\
\text { high C rates }\end{array}$ \\
\hline
\end{tabular}


Positive electrode degradation leads to chemical products of the positive electrode dissolved in the electrolyte in general metals. These products migrate from the positive electrode of the cell through the separator and reach the negative electrode. They can become a part of SEI layer formed on the negative electrode and not electrically conductive. This is called as Anode Poisoning. Therefore, this effect increases the overall resistance of the cell. This creates a clogging effect and prevents the flow of $\mathrm{Li}$, increasing the resistance.

The volume of particles in the electrode changes due to charging and discharging. The change in the volume is said to be anisotropic (different directions). This change in volume is about $10 \%$. When the particle is cracked, it becomes exposed to fresh graphite surface with the solvent which has not yet been covered by SEI film. The cracking of the particle occurs due to the change in the volume. This co-intercalation causes surplus SEI layer to grow inside the particle and causes additional particles to crack due to additional forces. This leads to exfoliation (layers flaking off) of graphite due to which it loses its ability to store $\mathrm{Li}$, reducing the capacity of the cell. In addition, gases are released when graphite interacts with the solvent. These gases expand and cause additional cracking of the material. The negative electrode itself consists of various non-active elements that include conductive additives to achieve conductivity and binders for binding the electrode particles together. Figure 6 shows particles of active materials placed below a current collector.

Active materials

\section{Conductive additive ::::}

(3)

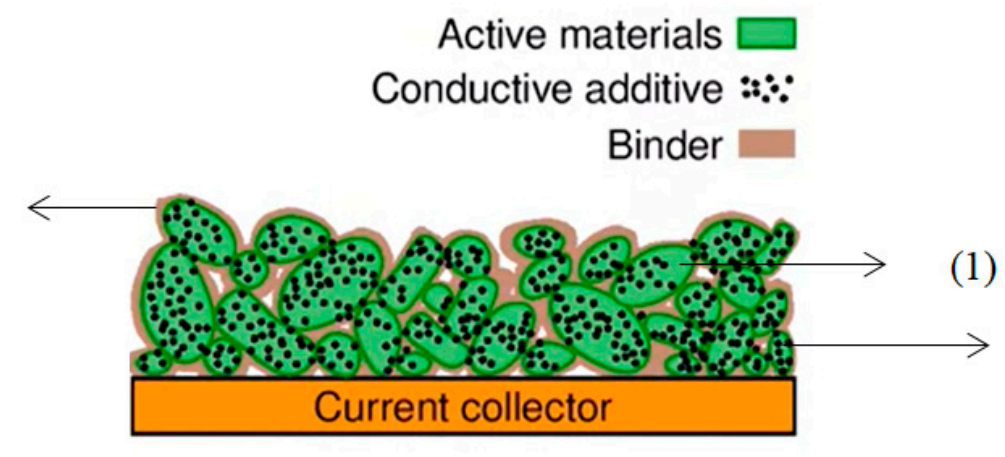

(1) Active Material - Lithium Oxide $\left(\mathrm{Li}_{2} 0\right)$

(2) Conductive Additive - Carbon (C)

(3) Binder - Resin

Figure 6. Composite materials in an electrode.

The stress on the electrode during charging and discharging the cell causes the particles to expand and contract. This causes fatigue to the non-active materials used at different locations. This reduces the current pathways through the electrode. This can happen between the particles or between the current collector and the particles or between binder and current collector. In a nutshell, the overall impedance increases as the particles are disconnected from each other.

When the cell is over discharged (below 1.5 V), Cu current collector corrodes release $\mathrm{Cu}^{2+}$ ions to the electrolyte. $\mathrm{Cu}$ material reacts with the electrolyte electrochemically. This reduces the contact between the current collector and the particles, leading to higher resistance. The $\mathrm{Cu}$ ions can deposit on the electrode and integrate with SEI, creating high resistance. However, the corrosion occurs at specific places creating non-uniform current and potential distribution internal to the cell. This can lead to accelerating Li plating at some parts of the cell. Table 4 shows the aging of the cell due to composite electrode materials used. 
Table 4. Aging due to composite electrode materials.

\begin{tabular}{cccc}
\hline Reason & Effect & Leading to & Enhanced by \\
\hline $\begin{array}{c}\text { Current Collector } \\
\text { Corrosion }\end{array}$ & Rise in Impedance & Power Fade & $\begin{array}{c}\text { Over discharge and } \\
\text { low cell SOC }\end{array}$ \\
\hline Binder decomposition & Loss of Li & Capacity Fade & $\begin{array}{c}\text { High SOC and } \\
\text { temperature }\end{array}$ \\
\hline $\begin{array}{l}\text { Contact between particles } \\
\text { due to change in volume }\end{array}$ & Loss of Li & Capacity Fade & Overcharge \\
\hline
\end{tabular}

\section{Aging Effects at Positive Electrode}

The degradation process in a positive electrode can occur in:

(a) At the electrode surface

(b) Within the bulk of the active material

(c) Inside the electrode

Most of Li ion cells use electrolyte containing $\mathrm{LiPF}_{6}$ as its salt. The oxidation of the electrolyte and the decomposition of the salt set to form a surface layer which is similar to the SEI layer discussed above. However, this severity is considered to be lesser than that of SEI on negative layer. The metals from the electrode dissolve in the electrolyte creating breakdown in the overall structure, as a result of which dissolved metal ions are left behind. These precipitate on the surface of the materials creating high resistance path. Electrodes of Manganese and Cobalt usually suffer from this problem. This effect is accelerated during high temperatures.

When Li intercalates with the crystalline structure of the positive electrode, structural defects are created and a change in volume is observed. This process is referred to Phase transitions and can lead to cracking. Some transitions are normal and can be reversed. The structure formed may not be capable of holding Li in it. However, others can destroy the shape of the structure.

When positive electrode of different composites is used, effects similar to that of negative electrode are observed. This leads to capacity fade. Table 5 shows the effects on positive electrode.

Table 5. Effects on positive electrode.

\begin{tabular}{cccc}
\hline Reason & Effect & Leading to & Enhanced by \\
\hline Phase transitions & $\begin{array}{c}\text { Cracking of active } \\
\text { particles }\end{array}$ & Capacity Fade & $\begin{array}{c}\text { High C rate, High } \\
\text { and Low SOC }\end{array}$ \\
\hline Structural Disorder & Loss of Li & Capacity Fade & $\begin{array}{c}\text { High C rate, High } \\
\text { and Low SOC }\end{array}$ \\
\hline $\begin{array}{c}\text { Metal dissolution and } \\
\text { electrolyte decomposition }\end{array}$ & $\begin{array}{c}\text { Migration of } \\
\text { soluble species }\end{array}$ & Capacity Fade & $\begin{array}{c}\text { High and low SOC, } \\
\text { temperatute }\end{array}$ \\
\hline
\end{tabular}

The effect of aging on the electrodes are not independent effects as reaction products formed on one side can diffuse to the other electrode and result in additional reactions. The electrolyte decomposition in batteries occurs at the end of charge at high potentials.

The main degradation process which occurs at the positive electrode is due to (1) Transition metal dissolution-migration and (2) Catalytic reduction. Initially, loss of Li ions from the positive electrode occurs due to the acid attack in Li ion cells. This effect becomes accelerated due to high temperature. This reaction occurs simultaneously and is termed as 'Dissolution Migration Catalytic Reaction'. This reaction is seen in all transition metal ions and majorly observed in Manganese.

Some of the major issues in Lithium Sulphur Batteries (LSB) are high self-discharge rate and aging are discussed. These issues are due to the dissolution of active materials 
in the electrolyte. In LSB, self-discharge occurred due to (a) direct chemical interaction of Sulphur and Li Polysulfides with the electrolyte and (b) Corrosion at the positive electrode. The batteries in which stainless steel is used as current collector (shown in Table 6), suffer from this problem.

Table 6. Shows different current collectors used in Li ion batteries [24].

\begin{tabular}{cl}
\hline Material & Electrode \\
\hline Aluminum Foil (Al) & \\
Al Mesh & Anode \\
Al Foam & \\
Etched Al & \\
Coated Al & \\
Cu Foil & Cathode \\
Cu Mesh & \\
Cu Foam & \\
Etched Cu & \\
Coated Cu & \\
\hline
\end{tabular}

It was found that the self-discharging during storage was caused due to the interactivity of the metallic Li electrode with Sulphur dissolved in the electrolyte. It was observed that capacity fade in LSB batteries occurred due to storage. Sulphur and Li compound $\left(\mathrm{Li}_{2} \mathrm{~S}_{\mathrm{n}}\right)$ dissolved in the electrolyte, interact with the electrode material and forms Li Sulphide $\mathrm{Li}_{2} \mathrm{~S}$ compound, which is insoluble. The deposition of $\mathrm{Li}_{2} \mathrm{~S}$ on the negative electrode and the unbreakable bond between Sulpher and $\mathrm{Li}_{2} \mathrm{~S}$ in the micro pores of the positive carbon electrode are the major reasons for capacity fade.

\subsection{Estimation of SOH Using Various Methods}

$\mathrm{SOH}$ is an indication of health of the battery and is a measure of long-term capability of the battery. It takes into account the effect of change in the internal resistance, capacity and effect of fast discharge leading to high temperature and self-discharge. During the lifetime of a battery, the performance deteriorates due to the irreversible physical and chemical reactions inside the battery. $\mathrm{SOH}$ is a relative term which is an estimate but not measurement. When the batteries are fresh, $\mathrm{SOH}$ would be $100 \%$. The $\mathrm{SOH}$ decreases if the battery is either left unused or entered service. Since, $\mathrm{SOH}$ is a relative term; the measurement system should keep a track of the initial condition or standard conditions.

Estimating $\mathrm{SOH}$ involves internal resistance and nominal capacity. Estimating the internal resistance is relatively simpler as it is can be measured by performing experiments. A 5-RC model is used to estimate $R_{0}$ :

$$
v_{k}=O C V+M h_{k}-\sum_{i} R_{i} i_{R i, k}-i_{k} R_{0}
$$

where $v_{\mathrm{k}}$ represents the terminal voltage $(V), O C V$ is Open Circuit Voltage $(V), M h_{k}$ represents the hysteresis component, $\sum_{i} R_{i} i_{R i, k}$ represents diffusion voltage $(V)$ and $i_{k} R_{0}$ represents the voltage drop due to internal resistance.

The sensitivity of the voltage measurement due to change in resistance can be termed as:

$$
S_{v_{k}}^{R_{0}}=\left(R_{0} / v_{k}\right) * d v_{k} / d R_{0}=-R_{0} i_{k} / v_{k}
$$

To ensure high order of sensitivity few assumptions are made as shown below:

1. High $R_{0}$

2. High $i_{\mathrm{k}}$ or

3. Low $v_{\mathrm{k}}$ 
High value of $R_{0}$ is not recommended. Similarly, high $V_{\mathrm{k}}$ is not recommended as over discharging is not preferred. Hence, high $i_{k}$ is recommended.

To account for the change in $R_{0}$ due to step change in current, the present sample of current is subtracted from the previous sample:

$$
\begin{gathered}
v_{k}=O C V_{(k)}+M h_{k}-\sum_{i} R_{i} i_{R i, k}-i_{k} R_{0} \\
v_{k-1}=O C V_{(k-1)}+M h_{k-i}-\sum_{i} R_{i} i_{R i, k-1}-i_{k-1} R_{0} \\
v_{k}-v_{k-1} \cong R_{0}\left(i_{k-1}-i_{k}\right)
\end{gathered}
$$

Term 1 -SOC changes with OCV is minimal and the curve is almost flat for almost all the chemistries. Hence, it is ignored.

Term 2-Change in hysteresis for one step change is minimal. Hence, can be ignored.

Term 3-Change in diffusion voltages for one step change is minimal. Hence, can be ignored.

Term 4 -Since, $i_{k}$ can change its value in one step time interval, term has to be considered. Hence,

$$
\hat{R_{0, k}}=\left(v_{k}-v_{k-1}\right) /\left(i_{k-1}-i_{k}\right)
$$

LHS of Equation (6) represents the estimated value of resistance.

Some of the issues associated with this method are illustrated.

\subsubsection{Case 1. Issue with Divided by 0}

Since, change in current exits in the denominator the resistance estimate is calculated only when the change in current is a non-zero number. Practically, this value of current is ignored when it falls below the threshold value defined by the user. The Enhanced Self Correcting (ESC) model parameters vary for different chemistries of the battery. Since, some of the terms in Equation (3) are ignored, $\hat{R_{0, k}}$ estimate can be noisy. Hence, a filter is employed to remove the noise considering the total least square approach based on Equation (7):

$$
\hat{R}^{f_{\text {filter }}}{ }_{0, k}=\alpha \hat{R}^{\text {filter }}{ }_{0,(k-1)}+(1-\alpha) \hat{R_{0, k}}
$$

where $\alpha$ (tuning factor) is between 0 and 1 . This equation is called as One Pole digital filter.

\subsubsection{Case 2. $\mathrm{R}_{0}$ Is a Function of $\mathrm{SOC}$}

If the variation of $R_{0}$ with respect to SOC is known, different values of resistances are assumed and by adapting resistance vectors an estimate of $R_{0}$ is found out.

\subsubsection{Case 3. ESR Dependence on Temperature}

Arrhenius equation shows that $R_{0}$ is dependent on temperature:

$$
R_{0}=R_{0, r e f} \exp \left(E_{R 0, r e f}\left(\frac{1}{T_{r e f}}-\frac{1}{T}\right)\right)
$$

Equation (8) is known as Arrhenius equation Where $R_{0, r e f}$ is the reference resistance at $T_{\text {ref }}(\mathrm{K})$ and Tuning factor is activation energy and $T_{\text {ref }}$ and $T$ in $\mathrm{K}$.

An innovative method for the balancing the $\mathrm{SOH}$ is seen in Figure 7. Battery power is fed to Bi-directional DC-DC converter feeding a common load. One of the main advantages of using this method is that the proposed scheme increases the life time of the battery and reduces the replacement cost. Simulations were performed using MATLAB/Simulink for a two-battery system having the chemistry as Lithium Cobalt Oxide $\left(\mathrm{LiCoO}_{2}\right)$. 
Battery 1 Capacity

To Gate Circuit

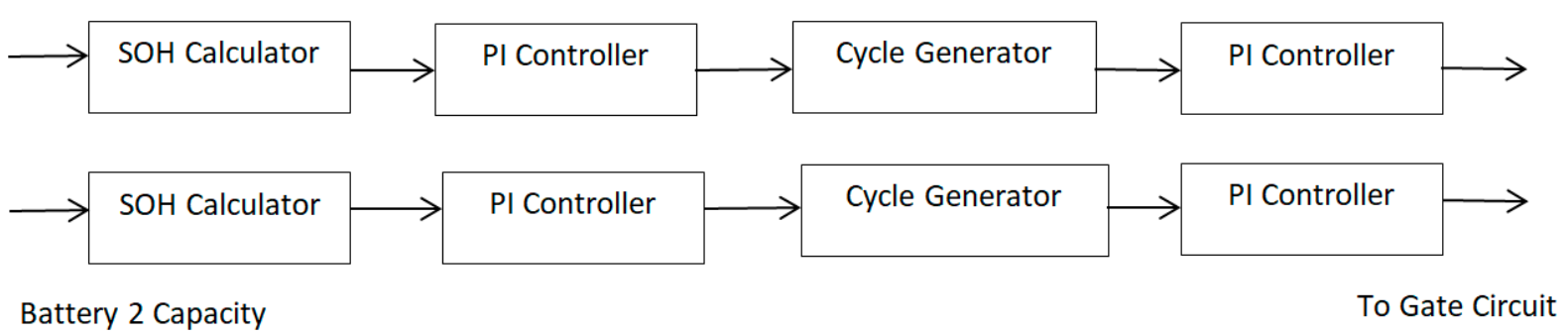

Figure 7. Control algorithm for $\mathrm{SOH}$ estimation.

$\mathrm{SOH}$ can be defined as:

$$
S O H=S O H+-C_{l e f t} / C_{t o t a l}
$$

where $C_{\text {left }}=$ number of cycles left over for the battery life to end $C_{\text {total }}=$ Total number of life cycles and $\mathrm{SOH}_{0}$ is defined as the initial $\mathrm{SOH}$.

The relationship between Depth of Discharge $(D O D)$ and total life cycle is defined as:

$$
C_{\text {total }}=a D O D^{-b}
$$

where $a, b$ depend of the type of battery and $D O D=1-S O C$. To determine the number of charge and discharge cycles, (11) was used.

$$
Q(t)=\int I(t) d t
$$

The PI controller checks for the current demand from the healthy cell and tries to keep up the $\mathrm{SOH}$ level, feeding continuous power to the load.

Figure 8 shows the block diagram representation to balance $\mathrm{SOH}$ level in a two-level battery scheme. Two batteries having different $\mathrm{SOH}$ levels are chosen. The output current from each cell is compared with the $\mathrm{SOH}$ levels and on $S O C$ levels provided by the main controller. The cell possessing higher $\mathrm{SOiH}$ had undergone more charging-discharging cycle till a point where the difference in $\mathrm{SOH}$ was zero. $\mathrm{DC}$ source fed the batteries during charging. After numerous charge-discharge cycles, battery having higher $\mathrm{SOH}$ matched with that of lower $\mathrm{SOH}$. The main controller provides the current reference signals during charging and discharging scenarios.

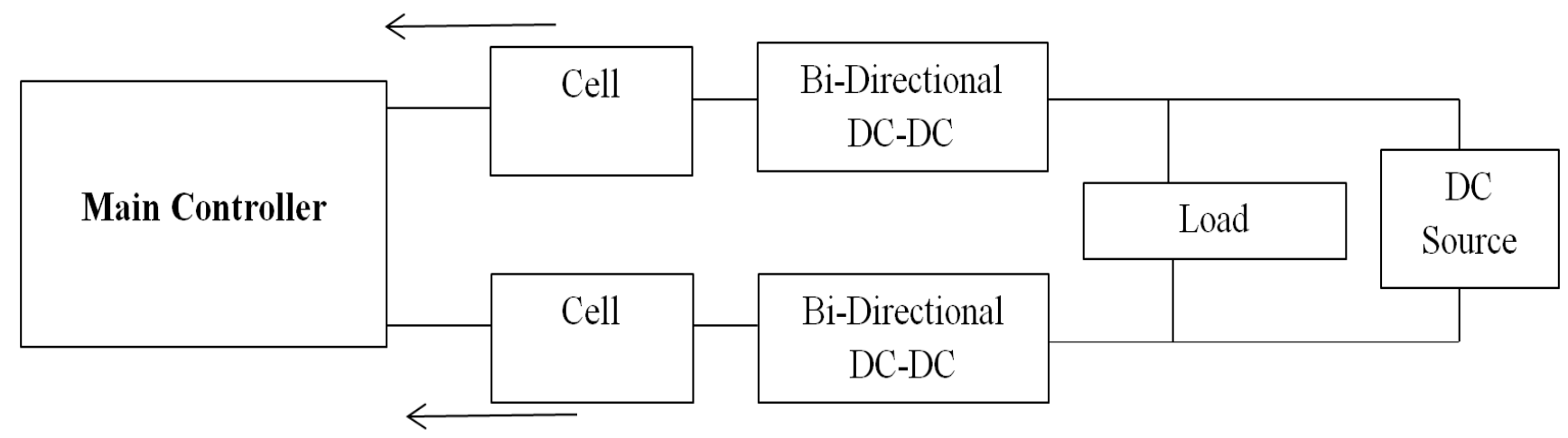

Figure 8. Balancing of $\mathrm{SOH}$ in two cell configuration.

The controller sets the command to discharge or charge the battery. The voltage for discharging and charging is $4.4 \mathrm{~V}$ and $3.6 \mathrm{~V}$, respectively, and the corresponding currents are $-2.2 \mathrm{~A}$ and $+2.2 \mathrm{~A}$, respectively. The SOC was varied from $50 \%$ to $100 \%$. Since, the SOC of cell -2 was much smaller and more aged than cell-1, it was varied from $100 \%$ to $80 \%$. 
An online estimation of SOH of battery combined with a PV cell based modified coulomb counting method simulated using MATLAB/Simulink. For SOH estimation, 2RC pair model of a RC was used in which empirical equations for Lithium Iron Phosphate cells were derived. Figure 9 shows a scheme for which $\mathrm{SOH}$ was estimated.
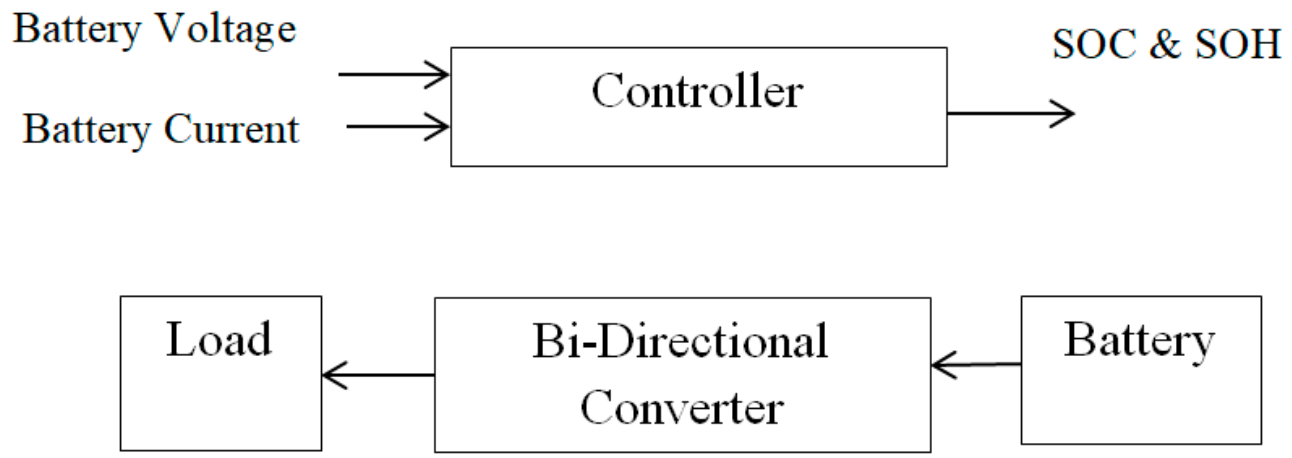

Figure 9. Scheme for which $\mathrm{SOH}$ was estimated.

A half bridge bi-directional converter was used to charge and discharge the battery of $48 \mathrm{~V}$ and $4 \mathrm{Ah}$. Voltage and current sensors were used to measure SOC and capacity. Figure 10 shows the flowchart employed for estimating $\mathrm{SOH}$.
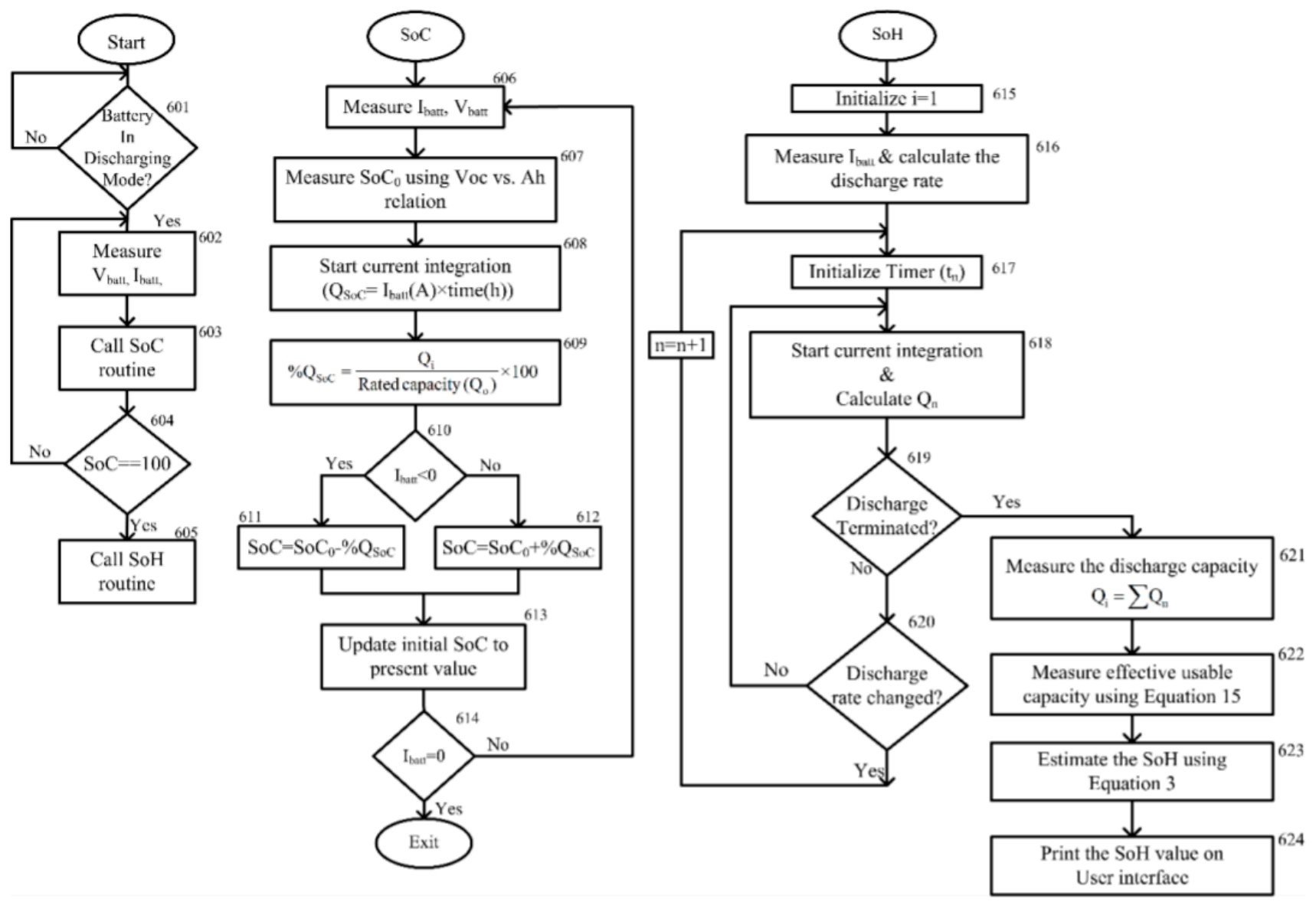

Figure 10. Flowchart for SOH estimation.

This algorithm was tested for two different scenarios (a) Complete Discharge and (b) Partial Discharge. In (a), simulation and experiment were performed for 450 cycles. The battery was discharged at $1 C$ rate. The controller computed the capacity after $100 \%$ DOD 
and $\mathrm{SOH}$ was found to be $90.875 \%$. The testing was performed at ambient temperature of $35^{\circ} \mathrm{C}$. Estimated $\mathrm{SOH}$ was found to be $84.15 \%$ for 1021 st cycle. During (b) conditions similar (a) were considered. The partial discharge process was stopped when the SOC was $66.3 \%$. The remaining capacity was $1.2 \mathrm{Ah}$ at the end of 450 cycles.

\section{Data Driven Approaches for SOH Estimation}

Some of the most common estimation models considered under ML are recurrent neural network (RNN), support vector machines (SVM), feed-forward neural network (FNN), regression model, clustering models and many more [25]. A few latest developments and estimation models under data-driven approaches for $\mathrm{SOH}$ estimation are reviewed in this section.

In [26], Healthy Features (H.F.) and Long-Short-Term-Memory (LSTM) methods are used to estimate the $\mathrm{SOH}$ of the Li-ion battery. The authors divided their process into three phases. During phase-1, battery testing and degradation analysis are performed. The battery test has been experimented on five cylindrical Li-ion batteries belonging to 21,700 and 18,650 types. The degradation data analysis was performed using Hybrid Power Pulse Characterization (HPPC) test. The second phase extracted the healthy features using Grey Relation Analysis (GRA) and Entropy Weight Method (EWM). Through GRA, extraction of five healthy factors that affect the $\mathrm{SOH}$ of a battery is performed. Further, with the correlation analysis with EMW, the extracted H.F. strongly correlates with the $\mathrm{SOH}$ of the Li-ion battery. Finally, in the third phase, LSTM (Long Short-Term Memory) network is applied to estimate the SOH. The LSTM gates use historical information and long-term dependency of time series data. Figure 11 shows the network architecture followed by LSTM. It can be observed that LSTM has input layers, hidden layers and output layers.

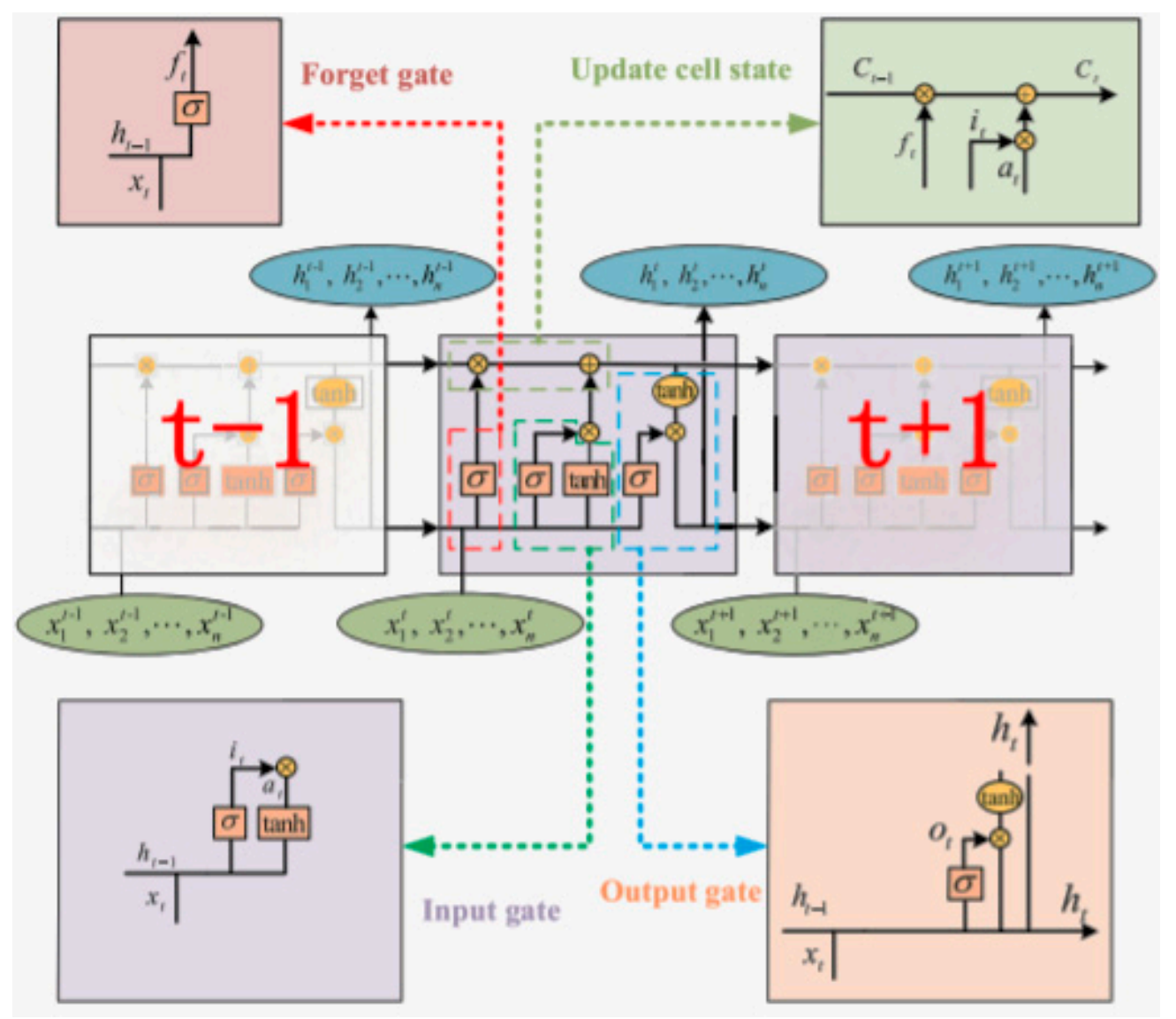

Figure 11. Network architecture of LSTM. 
The inner layer of LSTM uses a memory mechanism rather than the traditional neuron method. In LSTM, the input signals are mapped by a non-linear transformation into the output of the forgetting gate to generate a new cell and simultaneously controls the output gate. For training the LSTM parameters, Adam's optimal algorithm is used. Further, to evaluate the $S O H$ prediction, Maximum Absolute Error $(M A E)$, Mean Square Error (MSE), Root Mean Square (RMSE) and goodness-of-fit $R^{2}$ are considered shown in Equations (12)-(15).

$$
\begin{gathered}
M A E=\max \left|y_{i}-\hat{y}_{i}\right| \\
M S E=\frac{1}{m} \sum_{i=1}^{m}\left(y_{i}-\hat{y}_{i}\right)^{2} \\
R M S E=\sqrt{\frac{1}{m} \sum_{i=1}^{m}\left(y_{i}-\hat{y}_{i}\right)^{2}} \\
R^{2}=1-\sum_{i=1}^{m}\left(y_{i}-\hat{y}_{i}\right)^{2} / \sum_{i=1}^{m}\left(y_{i}-\bar{y}_{i}\right)^{2}
\end{gathered}
$$

During the prediction analysis, the training data size is varied as $30 \%$ to $70 \%$ of the test data. When $30 \%$ of total data was taken as the training set, the maximum prediction error was $6.70 \%$. However, as the training data increased to $60 \%$ of cycle data, the error lowered to $2 \%$. Even though the performance of LSTM outperformed from single Elman NN, SVM and GPR algorithms, it lacked the same understanding on a multi-cell experiment. In addition, they were able to obtain results only based on partial charging and discharging condition.

The authors in [27] introduced a hybrid data-driven method to predict SOH and remaining useful life (RUL) for Li ion batteries. The hybrid method includes Complete Ensemble Empirical Mode Decomposition with Adaptive Noise (CEEMDAN), Auto Regressive Integration Moving Average model (ARIMA) and Least Square Support Vector Machine (LSSVM). Initially, the performance of data analysis is carried out to extract the Health Indicators (HI) using CS2 series batteries dataset published by the CALCE Battery Research Group. Through dataset analysis, it was found that the charging and discharging voltage range was between $3.7 \mathrm{~V}-4.0 \mathrm{~V}$ and $4 \mathrm{~V}-3 \mathrm{~V}$, respectively. To establish the correlation between data series based on HI and capacity degradation, Pearson's linear coefficient, Spearman's rank and Kendall's tau correlation functions were used. Once the health indicators are extracted, a signal decomposition experiment is performed using CEEDMAN. The output of CEEDMAN was the trend and non-trend items. Further, the ARIMA was applied on-trend items to predict the SOH. Finally, the LSSVM was applied to the non-trend items to obtain the RUL. Through various experiments, it was observed that LSSVM predicted for a shorter period of time but had a large error when considered for a long term. Thus, ARIMA prediction on-trend and non-trend items improved the $\mathrm{SOH}$ prediction. Totally, 13 experiments were conducted on three batteries to obtain the trend and non-trend items. Hence, the implementation of CEEDMAN, ARIMA and LSSVM together on the trending and non-trending items displayed better prediction with less error. They lack in providing similar results for a full-life model of various batteries type.

XGBoost algorithm is used in [28] to estimate the SOH of Li ion battery. As this method was observer based, the computation and the complexity were high. Thus, to improve the prediction of $\mathrm{SOH}$, a data-driven model called XGBoost with Markova chain is used.

The experiments were performed on four Li ion batteries and the dataset was chosen from the NASA research center [29]. Two different kinds of experiments were conducted to obtain charging, discharging and impedance under a stable discharge experiment. In the first experiment, discharge data of \#5, \#7 and \#18 batteries were collected for the training set of the MC-XGBoost model. Battery\#6 battery discharge data was used to estimate the accuracy of the model. In the second experiment, the discharge data of \#5, \#6 and \#18 were considered for training the model. The discharge data of \#7 was used for the precision estimation model. Figure 12 displays the overall flow chart of MC-XGBoost. During the feature extraction phase, the voltage difference $(\Delta \mathrm{u})$, temperature difference $(\Delta \mathrm{T})$ and 
average voltage $\left(u_{-a v g}\right)$ were selected as potential features affecting the aging factor of the batteries. These factors were then fed to the MC-XGBoost model. Later, to compare the MC-XGBoost accuracy, the model was compared with other data-driven models such as the random forest method, the linear regression, $\mathrm{KNN}, \mathrm{SVM}$ on the data set of \#6 and \#7 batteries. The study observed that the prediction accuracy of MC-KGBoost and the random forest was higher than other methods and the prediction error of MC-XGBoost was close to real values. On further analysis, it was found that the average voltage gas greater influence on the accuracy of $\mathrm{SOH}$ prediction.

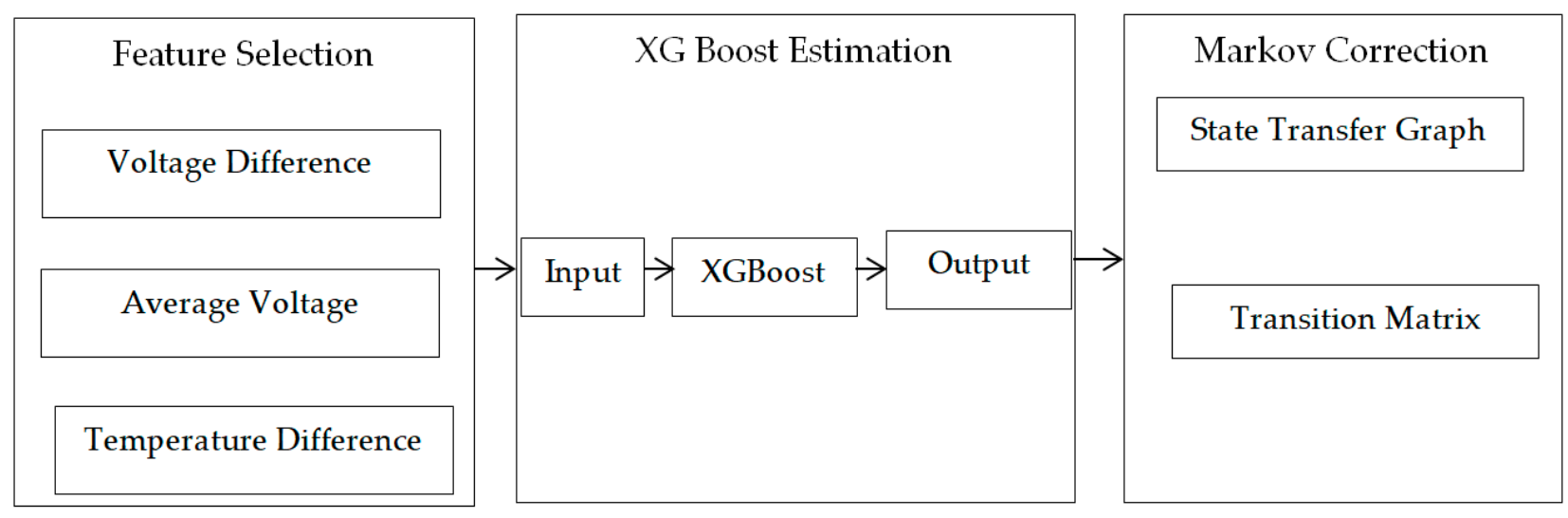

Figure 12. Flowchart of XGBoost and Markova Correction function in short MC-XGBoost model.

Using SVM on indirect health indicators, authors in [30] proposed a SOH estimation method. Three dynamic health indicators in the feature extraction phase depending on the charging and discharging curve were identified. Using a differential evolution algorithm, a Hybrid Differential Evolution Support Vector Regression algorithm (DE-SVR) was proposed to estimate accurate $\mathrm{SOH}$. In this case, 500 cycles of experiments on a dataset obtained by the Prognostics Center of Excellence, NASA Ames [31] was used. The dataset consisted of three 18,650 LIBS numbered \#5, \#6 and \#7 batteries from Idaho National Laboratory. Each battery had a $2.2 \mathrm{Ah}$ and $3.7 \mathrm{~V}$ of capacity and voltage, respectively. Each battery was made to run through three operations at $24{ }^{\circ} \mathrm{C}$. In the first operation, batteries were charged at a constant current of $1.5 \mathrm{~A}$ until the voltage reached 4.2V. Later, they were discharged to a constant voltage until the current dropped to $20 \mathrm{~mA}$. Finally, the batteries were discharged at a constant current of $2 \mathrm{~A}$ until the voltage reached the discharge cut-off voltage. The $\mathrm{SOH}$ estimation was evaluated by choosing the first 90 cycles as a training set, 91-120th cycle as a verification set and remaining as a test set. By comparing the proposed model with other existing models, the hybrid model realized a satisfactory performance in fitting the battery capacity degradation curve with an error of $<0.02$. Thus, DE-SVR demonstrated a higher accuracy using enhanced HI than original HI. However, the computation of DE-SVR was found to be higher than other models with the Gaussian regression model and partial method.

Root-mean-squared error-based machine learning was developed by the authors in [32]. By choosing the Gray/Black-box battery model, an electric equivalent circuit model was developed. This model took resistors; capacitor and inductor information into consideration and the experiment was performed on six Li ion batteries with different current and temperature levels. The first three batteries were modeled for the current level of $1.0 \mathrm{~A}$ and temperature $297.15 \mathrm{~K}$ followed by the next three batteries were modeled for 2.0 A current level and $277.15 \mathrm{~K}$ temperature. Knee Points were calculated on the dataset collected from NASA Ames prognostic [33]. By considering the Euclidean distance between the knee points, it was inferred that the relative health of batteries decreased with a decrease in the distance between the two points. The line between the two points is termed a pseudo-linear region. The input parameters for the ML model are chosen within 
the pseudo-linear region. Later, using the polynomial regression model of third degree under RMSE was derived. During the prediction phase, 30\% of discharge curve data was dedicated as a testing set and the remaining $70 \%$ of data was taken as the training set. The SOC percentage was derived using the voltage as a reference point on the pseudo-linear region and arm length. Further, by performing reverse engineering, the SOH estimation was derived. The entire experiment was limited to smaller data which may not be feasible for a larger dataset.

For an application that uses hybrid or fully electric vehicles, [34] proposed an ANNbased data-driven method to estimate SOC and $\mathrm{SOH}$ together. SOC estimation relied on the identification of aging factors and $\mathrm{SOH}$ estimation showed dependence on the behavior of SOC in a recursive closed-loop. From Figure 13, it can be observed that the system is divided into two subsystems. The first subsystem estimates the SOC using four regression ANNs and the second subsystem estimates $\mathrm{SOH}$. The output of the SOC subsystem is fed as input for the $\mathrm{SOH}$ subsystem as they were correlated on aging factors. Such setup is termed recursive loop architecture. The experiment was performed on a battery pack consisting of 168 cells (cell model-Kokam SLPB 11543140H5). The pack possessed nominal voltage and current of $48 \mathrm{~V}$ and $60 \mathrm{Ah}$, respectively, with 7C rate of discharge. The experiment was conducted for duration of $5000 \mathrm{~s}$ with 42 consecutive buffers and time length of $120 \mathrm{~s}$ for a mean capacity of $12 \mathrm{Mh}$.

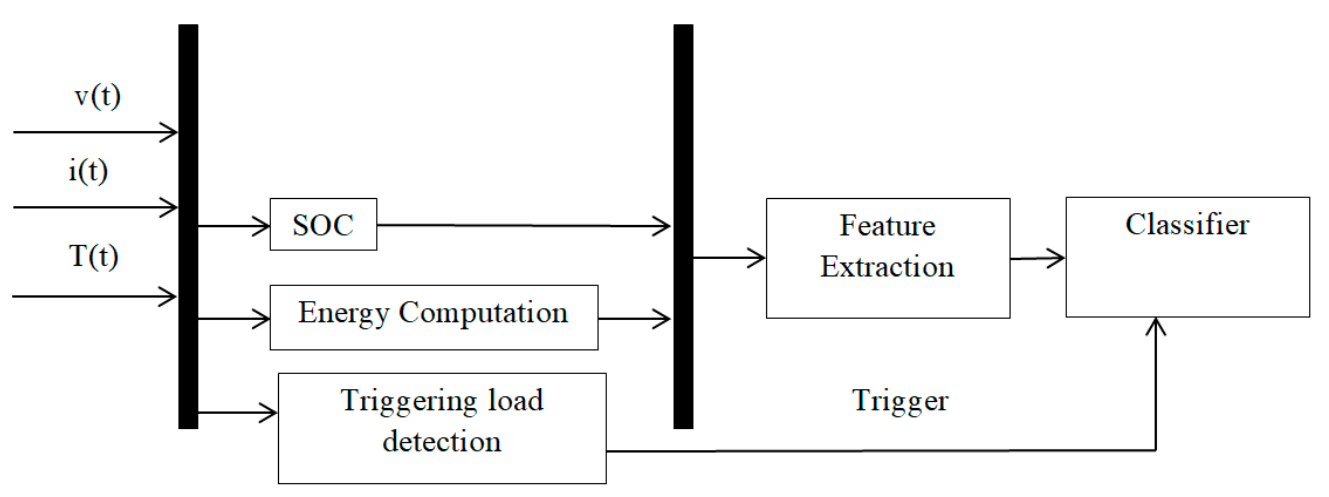

Figure 13. Recursive loop architecture to estimate of SOC and SOH using ANN.

During the verification of $\mathrm{SOH}$, a confusion matrix tool is used to estimate the accuracy. Figure 14 displays the classified and reported factors under rows and columns. The diagonal cell values are classified as correct classification and the off-diagonal values were misclassified. Through matrix analysis, it is found that the accuracy was equal to $2.4 \%$ of the misclassification (178 buffers) over the total number of test occurrences $(75,000)$. Finally, during the verification of SOC, a time series-based ANN regression is implemented. The ANN provides four outputs and each corresponds to the correct aging level of the battery. These selected values are input to the $\mathrm{SOH}$ classification as in Figure 14. The throughput error was found to be limited to $3 \%$.

In [35], a novel $\mathrm{SOH}$ estimation method is proposed based on the battery $\mathrm{T}_{\mathrm{s}}$. HI are extracted from the sample $T_{\mathrm{S}}$ by applying qualitative analysis on the Differential Temperature (DT) curve. HI vector containing 21 differential temperature values are extracted. With these HI vector values, MI and SVR are considered to establish the relation between DT and $\mathrm{SOH}$. The experiment evaluated two different sets of battery degradation datasets namely the Oxford dataset and the NASA dataset. The Oxford dataset consisted of battery aging of eight Kokam pouch cells with a nominal capacity of $740 \mathrm{mAh}$ and the NASA dataset contained battery degradation data from three 18,650 cells with cathode as $\mathrm{LiNi}_{0.8} \mathrm{Co}_{0.15} \mathrm{Al}_{0.05} \mathrm{O}_{2}$ and graphite anode with a little cell capacity of $2 \mathrm{Ah}$. The developed $\mathrm{HI}$ is validated against the Oxford and NASA datasets. Further, the results are compared with Incremental Capacity Analysis (ICA) for SOH. From the comparison, it was concluded 
the proposed SVR model showed overall better accuracy than the ICA model. In the future, a thermal image-based investigation would be performed.

\begin{tabular}{|c|c|c|c|c|c|c|}
\hline 峁 & 1469 & 19 & 2 & 0 & 0 & \\
\hline 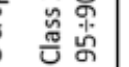 & 21 & 1459 & 15 & 0 & 0 & \\
\hline 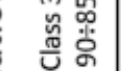 & 10 & 21 & 1467 & 15 & 14 & \\
\hline 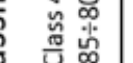 & 0 & 1 & 16 & 1472 & 21 & \\
\hline 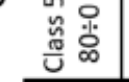 & 0 & 0 & 0 & 23 & 1465 & \\
\hline Error & $2 \%$ & $2.7 \%$ & $2.2 \%$ & $2.5 \%$ & $2.3 \%$ & $2.4 \%$ \\
\hline & $\begin{array}{c}\text { Class } 1 \\
100 \div 95\end{array}$ & $\begin{array}{l}\text { Class } 2 \\
95 \div 90\end{array}$ & $\begin{array}{l}\text { Class } 3 \\
90 \div 85\end{array}$ & $\begin{array}{l}\text { Class } 4 \\
85 \div 80\end{array}$ & $\begin{array}{c}\text { Class } 5 \\
80 \div 0\end{array}$ & \\
\hline
\end{tabular}

Figure 14. Confusion Matrix for SOH Estimation

A real-time $\mathrm{SOH}$ estimation is proposed in [36] using Equivalent Internal Resistance (EIR) of Li ion batteries. The work is divided into three stages. In the first stage, the co-relation between EIR and battery degradation is extracted. In the second stage, the EIR vector is derived using a fast extraction method and compared with SOC. In the last stage, SVR model is applied to estimate the real-time $\mathrm{SOH}$. Under $40^{\circ} \mathrm{C}$, the aging cycle experiment on three $15 \mathrm{Ah}$ lithium iron phosphate batteries for every 20 cycles. The internal resistance test was conducted after 7200 s. $20-90 \%$ of the EIR spectrum was collected and provided as input to the SVR model. Then the first set of EIR correspondent to 0.6 of SOC is selected as input for the SVR model. The results of regression and prediction were barely satisfying. To improve the results, a set of training data at 0.6 and 0.7 EIR vectors were added. This created a good amount of influence on the accuracy and prediction of $\mathrm{SOH}$. To further analyze, 0.8 EIR vector is used as input to SVR and was observed to have minimal error. Through these variations and analysis, they provided a high robust $\mathrm{SOH}$ estimation for simple battery degradation using EIR values. However, the robustness and accuracy of $\mathrm{SOH}$ for a complex working condition is yet an open challenge.

An adaptive ANN-based hybrid power estimation model is proposed in [37]. By considering variables including $\mathrm{SOH}$, current, ambient temperature and $\mathrm{SOC}$, two datadriven methods are proposed. Firstly, a model based on FFNN was used and the second model on OCV-SOC lookup table integrated with the voltage drop estimation. Before evaluating the proposed models, two EV tests were performed. In the first test, the Urban Dynamometer Driving Scheduling test (UDDS) [38] is used and in the second test Dynamic Stress Test (DST) [39] is performed. For the UDDS test, Li-ion batteries with 3.6 V, 16.5 Ah and 0.8 initial SOC were considered. The experiment was performed till SOC dropped to 0.76 (after $22 \mathrm{~min}$ ). The DST test was performed on $12.8 \mathrm{~V}, 150 \mathrm{Ah} \mathrm{Li}$-ion batteries with initial SOC $=1$. The DST test was executed for 115 DST cycles, till the battery was completely discharged, i.e., SOC $=0$ (after $690 \mathrm{~min}$ ). Figure 15 shows the experimental setup performing UDDS and DST test. 


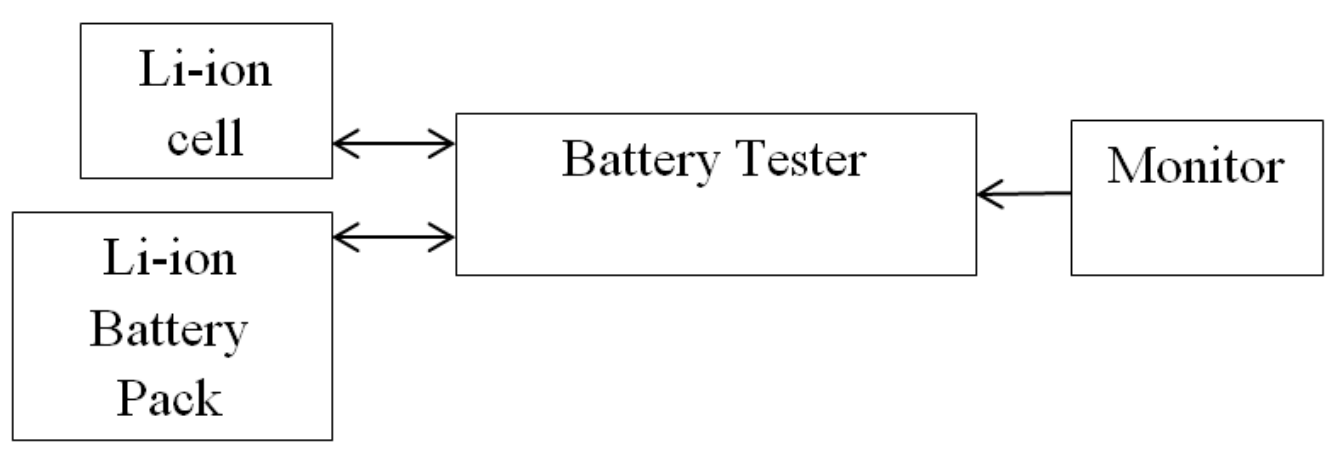

Figure 15. UDDS and DST test setup.

The obtained results were compared with linear, RC, ANN algorithms. From the comparison, it was observed that the results of the ANN and hybrid enhanced model were similar. Even though the accuracy of the proposed hybrid model was more for 15 and above hidden layers, the model accuracy decreased with less than five hidden layers.

In [40], a Prior Knowledge-based Neural Network (PKNN) and Markova chain are used to estimate the $\mathrm{SOH}$ of the Li-ion battery. The work is divided into three processes. In the first process, the features influencing the battery aging process are extracted using average voltage, voltage increments and the $\mathrm{d}(\mathrm{SOC}) / \mathrm{dV}$ (d stands for differential). In the second process, the battery utilization is estimated using PKNN. Finally, in the last process, the error is predicted using the Markova correction formula on the PKNN prediction. The experiment was conducted on the NASA battery dataset [41] and the commercial battery dataset containing an IFP1865140 type $\mathrm{LiFePO}_{4}$ battery. Three batteries were charged and discharged for 168 cycles, random 135 cycles data were chosen as a training dataset for PKNN, and the rest of the cycle data were used for testing. PKNN used two hidden layers of 19 nodes in each layer. The result of PKNN was compared with the state-of-the-art methods and found to achieve maximum accuracy of SOH estimation. PKNN showed an error rate of $2.5 \%$, but by applying Markova correcting on PKNN, the accuracy improved drastically and demonstrated a robust $\mathrm{SOH}$ prediction model.

A dual Gaussian Process Regression (GPR) model is used to estimate the $\mathrm{SOH}$ and RUL of Li-ion batteries back in [42]. HI are extracted using a partial charging curve obtained by the battery packaging test. Pearson correlation analysis is performed on factors influencing HI. Further GPR model is trained on a smaller dataset. The $\mathrm{SOH}$ threshold is used to evaluate if the battery pack is close to the End-Of-Life (EOF) of the battery. The experiment is performed on a battery pack consisting of four cells in series.

Figure 16 displays a flow chart of the dual GPR model. It can be observed that the HI is extracted based on the partial charging, voltage output, voltage drop and peak voltage. These HI are passed into RUL and SOH prediction models to obtain the threshold values. Finally, the prediction error is calculated for CI, MeAE, MaAE and RMSE. MaAE and RMSE were less than $1.3 \%, 0.4 \%$ for $10 \%$ of the training set. $\mathrm{T}_{\mathrm{S}}$ and inconsistent charge/discharge data were not considered during the prediction phase. To provide a reliable solution for a real-time environment requires larger training data. 


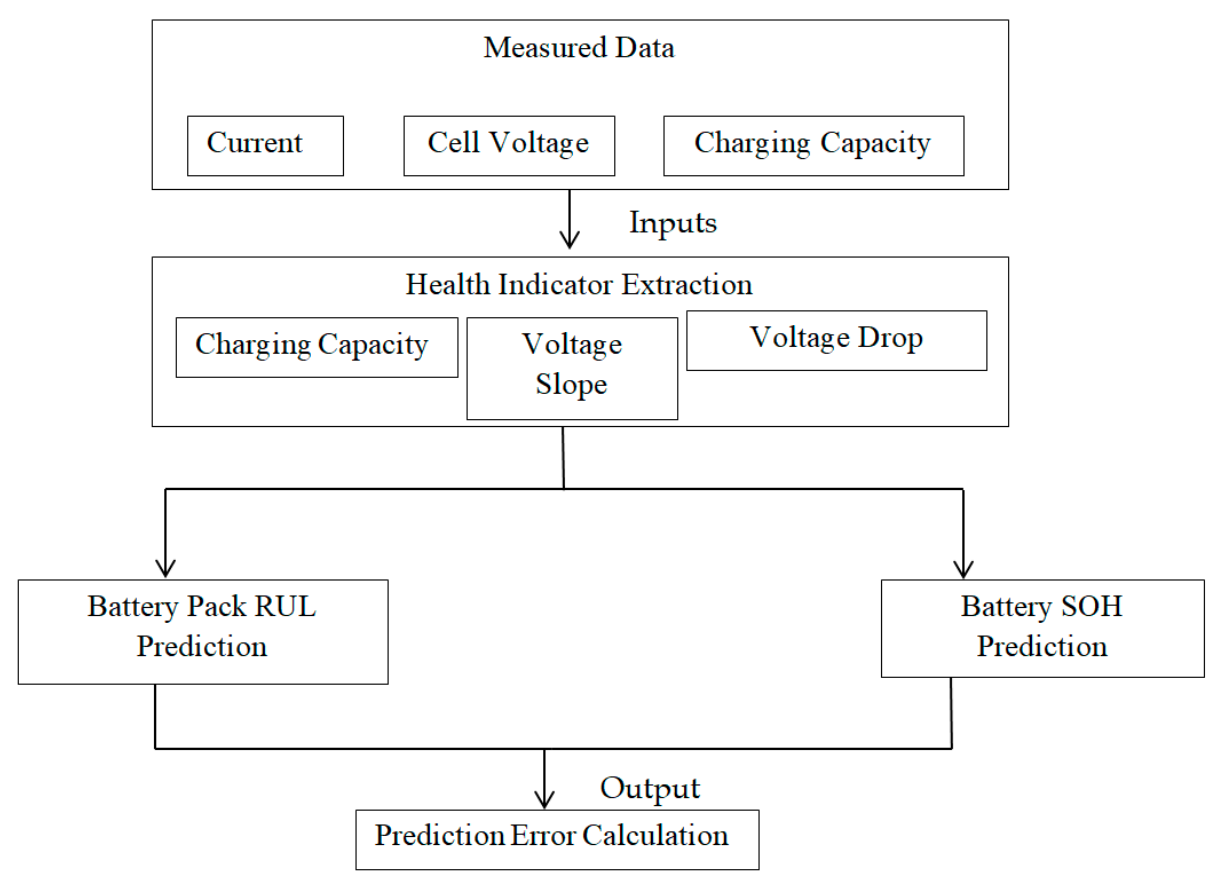

Figure 16. Flow chart of Dual GPR based SOH model.

\section{Conclusions}

$\mathrm{SOH}$ is one of the most fundamental algorithms in BMS. This estimation can be used either to estimate the increase in internal resistance or to estimate the reduction in the capacity of the battery. Direct estimation or Degradation models are used to estimate the aging. $\mathrm{SOH}$ degradation can also be due to increase in temperature and fast discharge from cell having low SOC etc. Conventional methods used to estimate $\mathrm{SOH}$ and their disadvantages are discussed in this paper. Recently, ML techniques are used for $\mathrm{SOH}$ estimation. The use of RNN, SVM, LSTM and ANN has improved the estimation of the $\mathrm{SOH}$ and RUL with reduced error rate. Even though the dataset size and various parameters matter in obtaining a precise accuracy, the researchers have found the use of ML and AI algorithm helps is predicting the SOH and RUL of the Li-ion batteries. The various experiments have shown that the finding the optimal $\mathrm{HI}$ benefits to the RUL and SOH estimation algorithms. Hence, it can be observed that the HI voltage and current values greatly influence the data-driven based estimation algorithms. With the advent of cloud computing, efficient BMS algorithms can be modeled and tested on an integrated platform. However, the current challenges in this regard are namely (1) effects on multi-scale integrated modeling methods and (2) Ability of the BMS controller to upgrade remotely (3) Variable atmospheric conditions and (4) Cell-Cell variations. Even though $\mathrm{LiFePO} 4$ cells did not exhibit major aging even up to $50 \%$ of capacity degradation, the effect of low temperature on this phenomenon has to be investigated. In the future papers, we will be incorporating the $\mathrm{SOH}$ degradation due to increase in temperature using machine-learning techniques.

Author Contributions: S.S.—conceptualization, methodology, writing—original draft preparation; V.R.-investigation, resources and visualization; S.S.W.-Supervision, and project administration. All authors have read and agreed to the published version of the manuscript.

Funding: This research received no external funding.

Institutional Review Board Statement: Not applicable.

Informed Consent Statement: Not applicable.

Data Availability Statement: Not applicable. 
Conflicts of Interest: The authors declare no conflict of interest.

\section{Nomenclature}

\begin{tabular}{|c|c|}
\hline EV & Electric Vehicle \\
\hline HEV & Hybrid Electric Vehicle \\
\hline BMS & Battery Management System \\
\hline SOC & State of Charge \\
\hline $\mathrm{SOH}$ & State of Health \\
\hline SEI & Solid Electrolyte Interface \\
\hline LAM & Loss of Active Material \\
\hline $\mathrm{RC}$ & Resistor Capacitor \\
\hline OCV & Open Circuit Voltage \\
\hline $\mathrm{T}_{\mathrm{c}}$ & Core Temperature \\
\hline $\mathrm{T}_{\mathrm{S}}$ & Surface Temperature \\
\hline $\mathrm{T}_{\mathrm{amb}}$ & Ambient Temperature \\
\hline DOD & Depth of Discharge \\
\hline ML & Machine Learning \\
\hline AI & Artificial Intelligence \\
\hline RNN & Recurrent Neural Network \\
\hline SVM & Support Vector Machine \\
\hline FNN & Feed Forward Neural Network \\
\hline $\mathrm{C}_{\text {left }}$ & Number of cycles left over for the battery life to end \\
\hline $\mathrm{C}_{\text {Total }}$ & Total number of life cycles \\
\hline DOD & Depth of Discharge \\
\hline Q & Capacity of the battery \\
\hline I & Current \\
\hline $\mathrm{HF}$ & Healthy Feature \\
\hline LSTM & Long Short Term Memory \\
\hline HPPC & Hybrid Power Pulse Characterization \\
\hline GRA & Grey Relation Analysis \\
\hline MAE & Maximum Absolute Error \\
\hline MSE & Mean Square Error \\
\hline RMSE & Root Mean Square Error \\
\hline CEEMDAN & Complete Ensemble Empirical Mode Decomposition with Adaptive Noise \\
\hline ARIMA & Auto Regressive Integration Moving Average \\
\hline LSSVM & Least Square Support Vector Machine \\
\hline $\mathrm{HI}$ & Health Indicator \\
\hline DE-SVR & Hybrid Differential Evolution Support Vector Regression \\
\hline ICA & Incremental Capacity Analysis \\
\hline EIR & Equivalent Internal Resistance \\
\hline UDDS & Urban Dynamometer Driving Scheduling \\
\hline DST & Dynamic Stress Test \\
\hline PKNN & Prior Knowledge-based Neural Network \\
\hline GPR & Gaussian Process Regression \\
\hline EOL & End Of Life \\
\hline UPS & Uninterruptible Power Supply \\
\hline
\end{tabular}

\section{References}

1. Surya, S.; Williamson, S. Energy Storage Devices and Front-End Converter Topologies for Electric Vehicle Application Accepted for Publication E-Mobility—A New Era in Automotive Technology; Springer: Berlin/Heidelberg, Germany, 2021.

2. Behabtu, H.A.; Messagie, M.; Coosemans, T.; Berecibar, M.; Anlay Fante, K.; Kebede, A.A.; Mierlo, J.V. A review of energy storage technologies' application potentials in renewable energy sources grid integration. Sustainability 2020, 12, 10511. [CrossRef]

3. Williamson, S.S. Energy Management Strategies for Electric and Plug-In Hybrid Electric Vehicles; Springer: New York, NY, USA, 2013.

4. Plett, G.L. Battery Management Systems, Volume I: Battery Modeling; Artech House: Norwood, MA, USA, 2015.

5. Vetter, J.; Novák, P.; Wagner, M.R.; Veit, C.; Möller, K.C.; Besenhard, J.O.; Winter, M.; Wohlfahrt-Mehrens, M.; Vogler, C.; Hammouche, A. Ageing mechanisms in lithium-ion batteries. J. Power Sources 2005, 147, 269-281. [CrossRef] 
6. Xu, J.; Deshpande, R.D.; Pan, J.; Cheng, Y.-T.; Battaglia, V.S. Electrode Side Reactions, Capacity Loss and Mechanical Degradation in Lithium-Ion Batteries. J. Electrochem. Soc. 2015, 162, A2026-A2035. [CrossRef]

7. Plett, G.L. Battery Management Systems, Volume II: Battery Modeling; Artech House: Norwood, MA, USA, 2015.

8. Muralidharan, A.; Sreelekshmi, R.S.; Nair, M.G. Cell Modelling for Battery Management System in Electric Vehicles. In Proceedings of the 2020 Third International Conference on Smart Systems and Inventive Technology (ICSSIT), Tirunelveli, India, 20-22 August 2020; Institute of Electrical and Electronics Engineers (IEEE): Piscataway, NJ, USA, 2020; pp. 558-564.

9. Surya, S.; Channegowda, J.; Datar, S.D.; Jha, A.S.; Victor, A. Accurate Battery Modeling Based on Pulse Charging using MATLAB/Simulink. In Proceedings of the 2020 IEEE International Conference on Power Electronics, Drives and Energy Systems (PEDES), Jaipur, India, 16-19 December 2020; pp. 1-3.

10. Surya, S. Mathematical Modeling of DC-DC Converters and Li Ion Battery Using MATLAB/Simulink. IGI Glob. 2021, 104-143. [CrossRef]

11. Lam, L.; Bauer, P.; Kelder, E. A practical circuit-based model for Li-ion battery cells in electric vehicle applications. In Proceedings of the 2011 IEEE 33rd International Telecommunications Energy Conference (INTELEC), Amsterdam, The Netherlands, 9-13 October 2011.

12. Surya, S.; Arjun, M.N. Effect of fast discharge of a battery on its core temperature. In Proceedings of the 2020 International Conference on Futuristic Technologies in Control Systems \& Renewable Energy (ICFCR), Malappuram, India, 23-24 September 2020; IEEE: Piscataway, NJ, USA, 2020.

13. Surya, S.; Bhesaniya, A.; Gogate, A.; Ankur, R.; Patil, V. Development of thermal model for estimation of core temperature of batteries. Int. J. Emerg. Electr. Power Syst. 2020, 21. [CrossRef]

14. Surya, S.; Marcis, V.; Williamson, S. Core Temperature Estimation for a Lithium Ion 18650 Cell. Energies 2020, 14, 87. [CrossRef]

15. Surya, S.; Samanta, A.; Williamson, A. Smart Core and Surface Temperature Estimation Techniques for Health-conscious Lithium-ion Battery Management Systems: A Model-to-Model Comparison. Preprint 2021, 2021070087. [CrossRef]

16. Lin, X.; Perez, H.E.; Siegel, J.B.; Stefanopoulou, A.G.; Li, Y.; Anderson, R.D.; Ding, Y.; Castanier, M.P. Online parameterization of lumped thermal dynamics in cylindrical lithium ion batteries for core temperature estimation and health monitoring. IEEE Trans. Control. Syst. Technol. 2012, 21, 1745-1755.

17. Surya, S.; Channegowda, J.; Naraharisetti, K. Generalized Circuit Averaging Technique for Two Switch DC-DC Converters. In Proceedings of the 2020 8th International Conference on Power Electronics Systems and Applications (PESA), Hong Kong, China, 7-10 December 2020; IEEE: Piscataway, NJ, USA, 2020.

18. Surya, S.; Williamson, S. Generalized Circuit Averaging Technique for Two-Switch PWM DC-DC Converters in CCM. Electronics 2021, 10, 392. [CrossRef]

19. Goud, J.S.; Kalpana, R.; Singh, B. An Online Method of Estimating State of Health of a Li-Ion Battery. IEEE Trans. Energy Convers. 2020, 36, 111-119. [CrossRef]

20. Chowdhury, S.; Bin Shaheed, M.N.; Sozer, Y. An Integrated State of Health (SOH) Balancing Method for Lithium-Ion Battery Cells. Comput. Sci. 2019, 5759-5763. [CrossRef]

21. Swierczynski, M.; Stroe, D.-I.; Kar, S.K. Calendar ageing of LiFePO4/C batteries in the second life applications. In Proceedings of the 2017 19th European Conference on Power Electronics and Applications (EPE'17 ECCE Europe), Warsaw, Poland, 11-14 September 2017; IEEE: Piscataway, NJ, USA, 2017.

22. Locorotondo, E.; Cultrera, V.; Pugi, L.; Berzi, L.; Pasquali, M.; Andrenacci, N.; Lutzemberger, G.; Pierini, M. Impedance spectroscopy characterization of lithium batteries with different ages in second life application. In Proceedings of the 2020 IEEE International Conference on Environment and Electrical Engineering and 2020 IEEE Industrial and Commercial Power Systems Europe (EEEIC/I\&CPS Europe), Madrid, Spain, 9-12 June 2020; pp. 1-6.

23. Yang, S.; Zhang, Z.; Cao, R.; Wang, M.; Cheng, H.; Zhang, L.; Jiang, Y.; Li, Y.; Chen, B.; Ling, H.; et al. Implementation for a cloud battery management system based on the CHAIN framework. Energy AI 2021, 5, 100088. [CrossRef]

24. Zhu, P.; Gastol, D.; Marshall, J.; Sommerville, R.; Goodship, V.; Kendrick, E. A review of current collectors for lithium-ion batteries. J. Power Sources 2021, 485, 229321. [CrossRef]

25. Vidal, C.; Malysz, P.; Kollmeyer, P.; Emadi, A. Machine Learning Applied to Electrified Vehicle Battery State of Charge and State of Health Estimation: State-of-the-Art. IEEE Access 2020, 8, 52796-52814. [CrossRef]

26. Wu, Y.; Xue, Q.; Shen, J.; Lei, Z.; Chen, Z.; Liu, Y. State of Health Estimation for Lithium-Ion Batteries Based on Healthy Features and Long Short-Term Memory. IEEE Access 2020, 8, 28533-28547. [CrossRef]

27. Yun, Z.; Qin, W.; Shi, W.; Ping, P. State-of-Health Prediction for Lithium-Ion Batteries Based on a Novel Hybrid Approach. Energies 2020, 13, 4858. [CrossRef]

28. Song, S.; Fei, C.; Xia, H. Lithium-ion battery SOH estimation based on XGBoost algorithm with accuracy correction. Energies 2020, 13, 812. [CrossRef]

29. Agogino, A.; Goebel, K. Mill Data Set. BEST Lab, UC Berkeley. NASA Ames Prognostics Data Repository. 2007. Available online: http:/ / ti.are.nasa.gov/prolect/prognostie-data-repository (accessed on 5 October 2007).

30. Liu, Z.; Zhao, J.; Wang, H.; Yang, C. A New Lithium-Ion Battery SOH Estimation Method Based on an Indirect Enhanced Health Indicator and Support Vector Regression in PHMs. Energies 2020, 13, 830. [CrossRef]

31. Saha, B.; Goebel, K.; Poll, S.; Christophersen, J. Prognostics methods for battery health monitoring using a Bayesian framework. IEEE Trans. Instrum. Meas. 2008, 58, 291-296. [CrossRef] 
32. Sheikh, S.S.; Anjum, M.; Khan, M.A.; Hassan, S.A.; Khalid, H.A.; Gastli, A.; Ben-Brahim, L. A Battery Health Monitoring Method Using Machine Learning: A Data-Driven Approach. Energies 2020, 13, 3658. [CrossRef]

33. NASA-Battery Data-Set, National Aeronautics and Space Administration. Available online: Https://ti.arc.nasa.gov/tech/dash/ groups / pcoe/prognostic-data-repository/battery (accessed on 12 May 2020).

34. Bonfitto, A. A Method for the Combined Estimation of Battery State of Charge and State of Health Based on Artificial Neural Networks. Energies 2020, 13, 2548. [CrossRef]

35. Tian, J.; Xiong, R.; Shen, W. State-of-Health Estimation Based on Differential Temperature for Lithium Ion Batteries. IEEE Trans. Power Electron. 2020, 35, 10363-10373. [CrossRef]

36. Tan, X.; Tan, Y.; Zhan, D.; Yu, Z.; Fan, Y.; Qiu, J.; Li, J. Real-Time State-of-Health Estimation of Lithium-Ion Batteries Based on the Equivalent Internal Resistance. IEEE Access 2020, 8, 56811-56822. [CrossRef]

37. Hussein, A.A. Adaptive Artificial Neural Network-Based Models for Instantaneous Power Estimation Enhancement in Electric Vehicles' Li-Ion Batteries. IEEE Trans. Ind. Appl. 2018, 55, 840-849. [CrossRef]

38. United States Enviromental Protection Agency (EPA). Available online: https://www.epa.gov/vehicle-and-fuel-emissionstesting/dynamometer-drive-schedules (accessed on 7 March 2018).

39. Electric Vehicle Battery Test Procedures Manual, Rev. 2 January 1996. Available online: https://avt.inl.gov/sites/default/files/ pdf/battery/usabc_manual_rev2.pdf (accessed on 7 March 2018).

40. Dai, H.; Zhao, G.; Lin, M.; Wu, J.; Zheng, G. A novel estimation method for the state of health of lithium-ion battery using prior knowledge-based neural network and Markov chain. IEEE Trans. Ind. Electron. 2018, 66, 7706-7716. [CrossRef]

41. NASA. PCoE Datasets: Battery Data Set. Available online: https://ti.arc.nasa.gov/tech/dash/groups/pcoe/prognosticdatarepository/ (accessed on 13 September 2018).

42. Hu, X.; Che, Y.; Lin, X.; Deng, Z. Health Prognosis for Electric Vehicle Battery Packs: A Data-Driven Approach. IEEE/ASME Trans. Mechatron. 2020, 25, 2622-2632. [CrossRef] 